\title{
Relação entre acompanhante e acompanhado: reflexões acerca do dispositivo amizade-clínica
}

\author{
Ricardo Wagner Machado da Silveira $\star$ \\ Universidade Federal de Uberlândia, Uberlândia, MG, Brasil \\ Resumo
}

\begin{abstract}
Este trabalho é baseado em uma tese de doutorado que pretende refletir sobre a relação terapêutica entre acompanhante e acompanhado e suas possiveis aproximações com a relação de amizade. Utilizamos como intercessores, por um lado, o conceito de amizade dos filósofos Nietzsche, Montaigne e Blanchot e a técnica da análise mútua desenvolvida pelo psicanalista Sándor Ferenczi, para problematizar os movimentos de proximidade e distância que ocorrem no acompanhamento terapêutico. Por outro lado, dialogamos com os conceitos de políticas de amizade em Foucault, agir político em Arendt e especialmente conceitos como o Fora, o devir, a transversalidade e outros criados por Deleuze e Guattari, fundamentais para a reflexão sobre a dimensão ética, estética e política da clínica do Acompanhamento Terapêutico.
\end{abstract}

Palavras-chave: amizade; clínica; política; acompanhamento terapêutico.

\section{Relation between accompanier and accompanied: reflections on the friendship-clinical device}

\begin{abstract}
This work is based on a doctoral thesis that aims to reflect on the therapeutic relationship between companion and accompanied and possible approaches to the budding relationship. We use as intercessors, first, the concept of friendship of the philosophers Nietzsche, Montaigne and Blanchot and mutual analysis technique developed by psychoanalyst Sándor Ferenczi, to discuss the movements of proximity and distance that occur in therapeutic monitoring. Moreover, we use the concepts of political friendship in Foucault, Arendt in political action and especially concepts such as Outside, becoming and transversal created by Deleuze and Guattari, fundamental for reflection on the ethical, aesthetic and political dimension of clinic the Therapeutic Accompaniment.
\end{abstract}

Keywords: friendship; clinical; political; therapeutic monitoring.

\section{Construindo o dispositivo amizade-clínica}

Este trabalho tem como objetivo relatar o percurso de investigação feito no campo da psicologia clínica, com a problematização da relação terapêutica a partir de aproximações com a concepção de amizade na filosofia de Nietzsche, Foucault e Blanchot, com a técnica da análise mútua concebida pelo psicanalista Sándor Ferenczi e com o conceito de agir político de Arendt e especialmente conceitos como o Fora, o devir, a transversalidade e outros criados por Deleuze e Guattari, fundamentais para a reflexão sobre a dimensão ética, estética e política da clínica nas práticas de acompanhamento terapêutico.

Ao pesquisar as várias concepções de amizade ao longo da história e na filosofia observamos que autores como Foucault (1981), Sennett (1995) e Arendt (2005) constatam um declínio da importância da amizade como relação política no cotidiano da polis na Grécia antiga, e um processo progressivo de esvaziamento da vida pública e de despolitização das relações sociais. Em contrapartida, ocorre um fortalecimento e expansão da vida privada na contemporaneidade, regulada por um hegemônico modelo familialista determinante dos papéis sociais e suas relações. De acordo com Ortega (2002) este lento processo histórico se deu por vários fatores como a incorporação do amor e da sexualidade no matrimônio, a incidência de um dispositivo biopolítico sobre a família, a "invenção" da infância e da adolescência entre outros.

\footnotetext{
^Endereço para correspondência: Universidade Federal de Uberlândia, Instituto de Psicologia. Av. Pará, 1720, Bloco 2C, Campus Umuarama - Umuarama. Uberlândia, MG - Brasil. CEP: 38400902. -E-mail: ricardo.silveira@ufu.br
}

Considerando o familialismo como um determinante histórico e social da caracterização e valoração das relações sociais instituídas, podemos dizer que este modo hegemônico e institucionalizado de conceber as relações sociais muito influenciam as teorias e técnicas psicológicas para a compreensão das relações interpessoais e particularmente das relações terapêuticas.

Fazer a análise de algumas das relações de poder exercidas na clínica, como é o caso do atravessamento das instituições do familialismo e da normalização nas práticas terapêuticas, constitui-se um dos nossos objetivos neste campo de investigação. É evidente que este objetivo tem tudo a ver com o projeto foucaultiano de análise crítica das instituições disciplinares da psiquiatria, da psicologia e do poder investido no saber médico para a determinação do normal e do patológico (FOUCAULT, 1979, 1995, 1996).

Nossa singela contribuição para o projeto foucaultiano de análise crítica das relações de poder no universo $p s i$ se refere à construção do que chamaremos de dispositivo ${ }^{1}$ amizade-clínica que possa abalar os alicerces das concepções hegemônicas e institucionalizadas do que se entende por uma relação terapêutica e suas vicissitudes e que, além

\footnotetext{
${ }^{1}$ Deleuze (1990) dirá que um dispositivo é como uma rede, uma meada, um conjunto multilinear composto por linhas de forças heterogêneas. Tais linhas não delimitam sistemas homogêneos como objetos, sujeitos, linguagens, etc., mas seguem direções variáveis, traçam processos sempre em desequilíbrio. Desenredar as linhas de um dispositivo é construir um mapa, cartografar os saberes e os poderes que conduzem à (re)produção de modos de subjetivação.
} 
disso, possa levar à abertura para a experimentação de novas formas de relação entre terapeuta e paciente, mais especificamente, entre acompanhante e acompanhado.

Para que o dispositivo amizade-clínica possa funcionar, a amizade aqui precisa ser pensada enquanto uma relação de incitação recíproca e de luta permanente, com a qual se pode viver uma infinidade de encontros diferentes daqueles institucionalizados pelo modelo familialista e assim vislumbrar a potência terapêutica e política da amizade ao se pensar os saberes e práticas da/na clínica.

\section{Da proximidade}

A amizade se dá por livre escolha, não somos obrigados a sermos amigos porque temos o mesmo sangue ou o mesmo patrimônio a ser herdado ou os mesmos interesses.

De modo algum pensamos numa relação simétrica de amizade entre terapeuta e paciente simplesmente, tal como bons amigos aristotélicos que se unem por semelhança em valores ou por interesses comuns (ARISTÓTELES, 1984). Pensar assim seria estar capturado pelo modelo familialista, onde se tem uma forte ideia de pertencimento, igualdade, consenso e reconhecimento que costuma marcar relações de subjugação.

O dispositivo amizade-clínica transversalizando a relação terapêutica, desafia terapeuta e paciente a se transformarem neste processo, onde o que prevalece é a hospitalidade ao estrangeiro, a abertura à alteridade ${ }^{2}$, numa tentativa de construção da confiança necessária para enfrentar as repetições paralisantes da vida que afetam o trabalho do terapeuta, que aparecem nas queixas e sintomas do paciente e que acabam por demarcar o exercício de uma clínica, muitas vezes impedida de promover a mudança e a produção de subjetividade.

Rolnik (1995) afirma que a clínica tem como vocação criar condições de acolhimento da alteridade e a construção de estratégias de suportabilidade da violência que se processa para quebrar as cristalizações paralisantes e doentias que capturam a subjetividade. A relação analítica não é simplesmente uma troca de interlocutores, mas, antes, uma aliança feita de confiança e abertura às turbulências da alteridade, onde "passa-se a desejar a alteridade em sua dimensão invisível, desejar essa condição que nos obriga a nos diferenciarmos de nós mesmos: uma espécie de amor pelo desconhecido e pela incerteza criadora" (ROLNIK, 1995, p. 165).

Temos convicção de que as experimentações vividas na relação terapêutica podem levar a possíveis transmutações da vida, que muitas vezes se dão através das quedas e crises experimentadas como afirma-

\footnotetext{
${ }^{2}$ A alteridade é a condição de afetar o outro no encontro, o que tem por efeito provocar mudanças irreversíveis nele; condição que é ao mesmo tempo e indissociavelmente, a de ser afetado neste encontro, o que tem por efeito desestabilizar e transformar a si mesmo. A alteridade é nossa condição de afetar e sermos afetados pelo outro, não só humano, o que provoca turbulência e transformações irreversíveis em nossa subjetividade essencialmente processual (ROLNIK, 1995).
}

ção trágica ${ }^{3}$ da vida. É deste modo que a confiança de que falamos se constitui, se fortalece e viabiliza o cuidado terapêutico propriamente dito.

Ao pensar a proximidade na relação terapêutica, deparamo-nos com a questão da mutualidade entendida como essa dimensão que está aquém ou além da assimetria entre terapeuta e paciente. Assimetria extensamente discutida e teorizada pelos psis no processo de institucionalização da relação terapêutica em que, dentre tantos aspectos, o terapeuta, supostamente, tem o poder de ajudar aquele que procura ajuda, e aquele que precisa de ajuda apodera o que tem o suposto poder de ajudá-lo.

De nossa parte, interessa pensar e experimentar a mutualidade na clínica como algo que pode enriquecer e intensificar os processos de subjetivação ali onde eles se encontram despotencializados e, para tanto, novas relações de poder precisam ser inventadas, experimentadas.

Para ajudar nossos pacientes e suas vidas capturadas por poderosas forças homogeneizantes, nos lançamos numa relação que, de acordo com um dos discursos instituídos na clínica, deve ser manejada mantendo-se uma distância instrumental para que se possa levar à diferenciação necessária.

Segundo Laplanche (LAPLANCHE; PONTALIS, 2001) a neutralidade é uma das qualidades que definem a atitude do analista no tratamento. Ele deve ser neutro quanto aos valores religiosos, morais e sociais, não dirigir o tratamento em função de um ideal qualquer e abster-se de qualquer conselho; neutro quanto às manifestações transferenciais, ou seja, "não entrar no jogo do paciente"; neutro quanto ao discurso do analisando, isto é, não privilegiar a priori, em função de preconceitos teóricos, um determinado fragmento ou um determinado tipo de significações.

Diferentemente disso, o que muitas vezes acontece nos encontros terapêuticos é um mergulho - às vezes imperceptível e fugaz - no indiferenciado, em que nos tornamos outros nesse processo onde se rompem, mesmo que momentaneamente, as fronteiras das identidades de terapeuta e paciente, a assimetria e neutralidade, de tal forma que, em meio à crise das identidades, nessa mutualidade que embaralha os lugares e códigos, podem advir novas formas de sentir, pensar e viver.

Neste processo de caos diferenciador não temos garantias, somente o desejo de diferenciação. Essa mistura, esse "entre" terapeuta e paciente, que não é nem de um, nem do outro, acaba por definir os contornos de ambos como efeitos pontuais desse devir ${ }^{4}$ sem início nem fim.

${ }^{3}$ Rolnik (1994) analisa o filme Confiança de Hal Hartley dizendo que o diretor realiza uma ética do trágico. No filme os personagens caem frequentemente, a queda é inevitável, alguns vivem a queda como vítima ou do destino ou de um "olho gordo" qualquer, acreditam ser possível evitar a queda e quando caem, ou se paralisam de terror ou se destroem. Este é o modo dramático. Outros decidem entregar-se à queda e problematiza-la, porque sabem que cair é inevitável e que de dentro da queda é possível reerguer-se transmutado, sem esquecer que não há qualquer garantia de que isso de fato venha a acontecer. Este é o modo trágico de viver a vida.

4 "O devir é um termo relativo à economia do desejo. Os fluxos de desejo procedem por afetos e devires, independentemente do fato de que possam ser ou não calcados sobre pessoas, imagens, identificações. Assim um indivíduo etiquetado antropologicamente como masculino, pode ser atravessado por devires múltiplos, aparentemente, contraditórios: devir feminino que coexiste com um devir criança, um devir animal, um devir invisível, etc. Não precisos nem gerais, mas 
Acreditamos que conceber o encontro nessa perspectiva da processualidade e vive-lo efetivamente na clínica, é particularmente necessário para que possamos construir vínculos com pacientes enclausurados no Fora, ${ }^{5}$ os chamados psicóticos, os casos ditos graves ou aqueles que estão em crise.

Para tanto, pensar a mutualidade na clínica, nos proporcionou bons encontros. Um dos mais surpreendentes foi com Sándor Ferenczi, psicanalista do círculo de Viena e grande experimentador, que concebeu e aplicou a "técnica da análise mútua" com alguns pacientes psicóticos.

Para Ferenczi (1990) o paciente é um ser que precisa de amor e de aprender a amar, como se todos fossem crianças abandonadas e sofrendo, precisando ser cuidadas. A criança carente e abandonada sofre em meio ao caos indiferenciado. Ela constrói um "porto seguro" dentro da indiferenciação, como um porto seguro dentro do mar caótico do Fora. Trata-se de uma luta para dar forma, contorno, à subjetividade em colapso, nesse vazamento selvagem de elementos heterogêneos, que não consegue refrear esses fluxos e, consequentemente, produzir sentidos, atualizar existência.

Nesse cenário, Ferenczi convida o analista a desempenhar estrategicamente o papel materno, a relação no nível dos afetos, na dimensão do não representacional, para que, com o decorrer do processo, possa se incluir o universo dos nomes, da representação, do papel paterno. Esse convite ferencziano aposta no caos, no Fora, como condição de possibilidade de processos de diferenciação e movimentos de existencialização.

A prioridade ao não representacional nos remete à ideia da produção pática de subjetividade, o pático entendido como não discursivo, dado como uma subjetividade em direção à qual se vai, subjetividade absorvedora, dada de imediato em sua complexidade. O paradoxo consiste no fato de que a subjetividade pática tende a ser constantemente evacuada das relações de discursividade, mas é essencialmente na subjetividade pática que os operadores discursivos se fundam (GUATTARI, 1992).

A comunicação entre mãe e filho se faz de um modo eminentemente não representacional e, portanto, mais exposto às turbulências da indiferenciação, mas com ricas possibilidades de diferenciação. Por isso, a análise para Ferenczi, baseia fundamentalmente seu poder mutativo ou operante, no fato de ser uma experiência sem que se possa dizer, a cada momento, o que daquilo que foi dito ou vivido teve, efetivamente, o poder de produzir mudanças.

\footnotetext{
imprevistos. 'O devir é sempre entre ou no meio: mulher entre as mulheres, ou animal no meio de outros. Mas o artigo indefinido só efetua sua potência se o termo que ele faz devir, por si mesmo despojado das características formais que fazem dizer O, A (o animal que aqui está [...])"” (DELEUZE, 1997, p. 11-12).

5 "O Fora irrompe com suas partículas singulares e não ligadas, no jogo selvagem e aleatório das forças e entre-forças, vertiginosa tempestade de fluxos (corpo dilacerado, objetos parciais, pedaços, intensidades travessas, não significadas). Trata-se dos Elementos na indeterminação e indecisão de seu devir. Devir-louco, diria Deleuze. Sugado pelo vórtice, o nome próprio do sujeito é arremessado ao entrechoque de uma multiplicidade virginal - ou de uma organização, a promessa de uma consistência. Nem unidade, nem acúmulo possível. Ductilidade turbilhonar do puro devir das partículas elementares. A irrupção do Fora distende o sujeito louco segundo a diagonal do Acaso". (PELBART, 1989. p. 141).
}

É justamente com esta aliança, com esta continência e confiança, que se prepara o terreno para um encontro turbulento, mas potencialmente produtor de diferenciação.

Diferentemente de Freud que destaca o manejo da transferência como fundamental na análise, Ferenczi parte do conceito de introjeção onde há, na verdade, uma expansão, um abraço, um engolfamento de representações e afetos do real, onde a separação mais clara do mundo fantasmático e do real, obtidos pela análise, se dá a partir de uma fluidificação total, de um caos transitório, de onde se possa reconstruir em melhores condições a estrutura psíquica e sua economia pulsional.

Corajosamente ele expõe sua abertura à indiferenciação, mas seriamente comprometida com a conexão, com o encontro e produção do novo, a partir de elementos intensos da experiência analítica, como o corpo, o tato, o relaxamento ou clima amistoso na sessão, a importância do papel materno na análise (BIRMAN, 1988).

A técnica da análise mútua foi uma das estratégias mais contundentes e disruptivas que este psicanalista experimentou, mesmo que temporariamente, mas com a ousadia de um grande experimentador capaz de levar às últimas consequências sua abertura à indiferenciação para encontrar o outro. A análise mútua é uma técnica que se baseia na ideia de que, onde o analista é incapaz de oferecer ao paciente um amparo idôneo, deverá, pelo menos, fornecer-lhe pontos de referência; expondo ao paciente suas próprias fraquezas e sentimentos, com toda sinceridade de que for capaz.

Os protagonistas da situação analítica percebem um no outro, forças obscuras em ação, o que faz com que eles não pareçam inteiramente inofensivos. Ambos experimentam o mesmo sentimento de insegurança. A análise mútua visa elucidar essas zonas de sombra para permitir, a cada um, situar-se em relação ao outro.

Dessa forma, Ferenczi (1990) acredita ser possível a desmistificação de esperanças de uma contratransferência para apostar numa relação de sinceridade e benevolência não passional, numa aprendizagem e força para suportar perdas, o que aceleraria o processo de desligamento da análise e do analista.

A análise mútua, inicialmente foi uma proposta de duas de suas pacientes e que foi levada a sério por ele. Ferenczi tinha dois divãs em seu consultório, ele se deitava em um e a paciente no outro, ambos simultaneamente começavam a associar livremente. Na citação abaixo podemos testemunhar a potência terapêutica e disruptiva da técnica da análise mútua.

$\mathrm{O}$ analista foi capaz, através de suas associações livres e em relaxamento simultâneo com o paciente, de vincular pela primeira vez, sentimentos a esse evento originário (trauma) e conferir, assim ao evento o sentimento de uma experiência real. Simultaneamente, a paciente conseguiu adquirir uma intuição mais penetrante do que antes, da realidade desses eventos, tão frequentemente repetidos de forma intelectual. É como se duas metades da alma se completassem para formar uma unidade. Os sentimentos do analista entrelaçam-se com as ideias do analisado e as ideias do analista (imagens 
de representação) com os sentimentos do analisado. Desse modo, as imagens que de outro modo permaneceriam sem vida tornam-se episódios, e as tempestades emocionais, sem conteúdo, enchem-se de um conteúdo representativo (FERENCZI, 1990, p. 45).

Para nós, é nítida a riqueza desse tipo de experimentação, as possibilidades de conexão, de criação de sentido e produção de subjetividade se ampliam. A impressão que temos é de testemunhar o relato de um método de criação de sentidos, espécie de composição por associação livre de elementos singulares que vão se atravessando e compondo sentidos.

É óbvio que esta técnica teve polêmicos desdobramentos, um dos mais importantes com o próprio Freud e seu princípio de neutralidade, uma das regras fundamentais da análise que funciona como estratégia para evitar o risco de atitudes moralistas e diretivas do analista e desta forma, limitar o exercício de uma relação de poder do terapeuta sobre o paciente.

Por outro lado, vale lembrar que a ideia de diálogo dos inconscientes foi inicialmente concebida por Ferenczi (1990) e desenvolvida por Freud quando este instaura uma espécie de horizontalidade na comunicação entre o inconsciente do analisando e o inconsciente do analista através da ideia de que o analista deve ter sua atenção sempre flutuante e o analisando se esforçar para fazer a associação livre de ideias.

No acompanhamento terapêutico são recorrentes os relatos de cenas que remetem à vivência da mutualidade, da indiferenciação e perda temporária de contornos dos papéis de acompanhante e acompanhado que podem levar a processos de diferenciação e fortalecimento do vínculo entre os envolvidos. Acreditamos que, pelo menos em parte, isso se deve ao fato de que o acompanhamento terapêutico é um trabalho caracterizado pela grande proximidade entre as partes, que ocorre num cenário que é o cotidiano do acompanhado, justamente onde as marcas de sua história e de seu sofrimento se mostram de forma mais contundente, onde suas relações interpessoais significativas são vividas e, onde acontecem transferências maciças (MAUER; RESNISK, 1987).

Um exemplo é o caso de Pedro relatado no texto de Sereno, Aguiar e Mendonça (1991), ele tem 33 anos, primeiro surto psicótico há 12 anos com tentativa de suicídio para salvar a humanidade, apresentando ideação delirante persecutória e grande dificuldade de estabelecimento de vínculos sociais. Uma equipe com três acompanhantes terapêuticos passa a atender Pedro em sua residência. A primeira cena que nos interessa diz respeito ao trabalho do acompanhante Leonel com Pedro. No início, relata Leonel, as idas ao apartamento de Pedro caracterizavam-se pela ausência de relação, conversas que mal se entabulavam, clausura na residência, rejeição de Pedro que mandava Leonel ir embora constantemente. Certa vez, se entabula uma conversa com palavras sem nexo que dura por mais de uma hora e parecia que Pedro nunca mais ia parar. Leonel sai do apartamento de Pedro com muita dor no corpo: "Meu corpo havia dado o limite da proximi- dade e indiscriminação que poderia haver entre Pedro e eu [...] nossa relação não se daria a partir de um jogo de palavras, mas a partir de um jogo de corpos" (SERENO; AGUIAR; MENDONÇA, 1991).

No encontro seguinte volta a se instalar a barreira de contato e é como se Pedro dissesse para Leonel que este entrou em contato com ele, mas, em seguida foi embora e por este motivo, Pedro novamente se fechou para o encontro. Para Leonel, Pedro queria a fusão psicótica de corpos e o acompanhante não suportaria ficar indiscriminado na loucura do acompanhado.

Diante do negativismo de Pedro e de seu enclausuramento, Leonel, literalmente pega o acompanhado pelo braço e arrasta-o para saídas diversas e ele sempre reluta. A partir daí Pedro deixa de mandar Leonel embora, mas continua relutante a sair do apartamento. Cansado, Leonel deixa de dar a continência corporal demandada por Pedro por algum tempo, mas assim que volta a fazê-lo e puxa Pedro pelo braço para mais uma saída, este reage, consegue desvencilhar o braço e arremessa um soco no peito de Leonel. O acompanhante vai tirar satisfação com Pedro que se coloca em posição de briga, Leonel se atraca com ele e tudo termina com Leonel empurrando Pedro que sai correndo.

Ao que tudo indica Pedro pedia contorno corporal com toda a violência de sua esquizofrenia, como quem pergunta: Será que você aguenta? Depois disso a relação de ambos melhorou novamente, Pedro foi gradativamente interagindo com Leonel e seu corpo, de outros modos menos enérgicos e onde a interação amistosa foi se dando. Como bem disse Leonel:

A intervenção consistiu em estar junto, corpo a corpo [...] Pedro me dizia: 'o mundo é imenso, e por isso ele choca'. O nosso desafio era poder de alguma forma circular nesse 'mundo terrível'. O desafio de Pedro era estar no mundo e o meu desafio era estar com ele nesse mundo (SERENO; AGUIAR; MENDONÇA, 1991, p. 75).

Outra cena envolve a acompanhante Débora que também atendia Pedro, quando ele a conhece passa a chamá-la de "vidinha", ela sente que ele está convidando-a a compartilhar com ele esta parte de seu mundo e ela então passa a se arriscar a entrar no seu mundo presa nesse lugar concretizado por esta palavra. A acompanhante analisa que a palavra "vidinha" poderia ter dois significados, "de um lado trazia a possibilidade de saídas extremamente criativas" como a que fizeram ao bairro Liberdade e todas as perambulações pelo bairro que resultou no preparo de um risoto shopsuey que ele prepara em casa. Por outro lado, "vidinha" remete ao cansaço e angústia da acompanhante no final de alguns atendimentos, ela demora algum tempo para entender a face mortal da "vidinha" que tem algo de totalizante, absoluto, de fusão e simbiose, colocando em evidência um lado estranhamente amoroso da figura materna. A ideia era construir, com o acompanhado, cenas que remetam à sua vida (ou à vidinha?!), à sua história e é uma dessas cenas que pretendemos 
utilizar para cartografar suas ressonâncias com a problematização da mutualidade e da amizade e sua potência terapêutica (SERENO; AGUIAR; MENDONÇA, 1991).

Era um domingo, a dupla volta do centro da cidade onde foram comprar linguiça para o almoço, Débora lava a louça, Pedro prepara a mesa, ele lembra que sua mãe diz que "a mulher fica em casa e o homem sai para trazer as coisas", um faz o suco, outro traz os talheres e pratos, o clima é familiar, os dois almoçam e Pedro pergunta se eles são casados, a acompanhante pergunta se ele se lembra do dia do casamento, ele diz que não e em seguida diz que não quer retirar a mesa para se lembrar que Débora esteve ali. Recordar é viver é a música que ela começa a cantar e ele acompanha. O clima é de paixão. Ela diz:

Estou chapada no seu sorriso e nos seus olhos verdes brilhantes, que olham para mim, ou talvez até me atravessem enquanto canta. Deixei de vê-lo e estou remetida a mim... que relação é essa...que difere daquilo que sua mãe diz como deve ser e que também não é um casamento [....] $\mathrm{O}$ prazer pela construção mesma da cena é imenso para ambos, mas é como se eu tivesse me perdido dentro dele...é como se eu perdesse o meu lugar. É como se um morresse a cada vez que o outro tenta se discriminar [...] é exatamente o que ocorre na relação de Pedro com sua mãe (SERENO; AGUIAR; MENDONÇA, 1991, p. 76).

A cena se conclui com Débora propondo outra atividade e antes de ir embora cuida de retirar os pratos da mesa, marcando o fim do almoço e do horário de atendimento.

As duas cenas mostram a mutualidade vivida no acompanhamento terapêutico, a perda temporária dos contornos e dos lugares de acompanhante e acompanhado, as possibilidades de compreensão significativa do que se passa com o acompanhado e a possibilidade de, a partir do encontro na indiferenciação e mistura dos corpos, alçar-se voos para a superfície da diferenciação e da possibilidade de estar no mundo e/ou estar com o outro no mundo, como bem disse Leonel.

Para dar maior consistência à ideia da potência terapêutica da proximidade sem limites e fazer funcionar o dispositivo amizade-clínica, podemos aproximar amizade de mutualidade através de Montaigne e sua amizade singular com La Boétie.

A partir dos seus Ensaios, Montaigne (1972) apresenta o tema da amizade como centro de sua produção criativa inaugurada pela vida e particularmente pela morte de seu maior amigo, Etienne de La Boétie. Esta obra encena a grande crise de Montaigne: a perda do amigo é também o seu próprio desabamento.

A amizade tem em Montaigne um vasto sentido, desafia a moderação e as virtudes da amizade aristotélica.

Perda e busca, tramarão, portanto, juntas essa vida extravagante que se recusa a aderir a si mesma, que não descansa mais numa identidade, e por isso se ensaia sempre, na indeterminação... De fato, a vida do pensamento tem parte com a morte (CARDOSO, 1987, p. 161).

Montaigne busca os contornos de um eu a que aquela amizade, enigmaticamente parecia conferir consistência, chora a morte do amigo e o faz num esforço de afirmar sua própria existência através de sua obra. Num processo autopoiético, o pensamento tateia uma forma através da escrita e assim Montaigne afirma sua vida. Em seu luto Montaigne afirma: "Apenas ele desfrutava da minha verdadeira imagem e levou-a consigo. É por isso que me decifro a mim mesmo curiosamente" (MONTAIGNE, 1972, livro III, p. 9). Ele pensa a amizade e pensa-se nela. Decifra-a e decifra-se, traçando, em carne viva seu auto retrato. Este é um dos motivos que tornam o seu texto potente, intempestivo e não capturado por uma interpretação rasteira que trataria este complexo processo simplesmente como uma identificação narcísica (CARDOSO, 1987).

A força desta rara amizade ressoa nas experiências de mutualidade descritas por Ferenczi ou nas cenas de acompanhamento terapêutico. Em passagens do texto "Da Amizade" onde Montaigne descreve "a intimidade sem reservas". Diz ele:

$\mathrm{Na}$ amizade a que me refiro, as almas entrosam-se e se confundem uma na outra, numa mistura em que não se distinguem, em que não encontram mais a costura que as juntou. Se insistirem para que eu diga por que o amava, sinto que o não saberia expressar senão respondendo: porque era ele; porque era eu (CARDOSO, 1987, p. 98).

Montaigne vai construindo seu pensamento sobre a amizade na falta do amigo, uma vida que se afirma e se extravasa nos Ensaios, livro que interroga e rejeita qualquer ordem natural, divina ou familiar que comande do alto a virtude das boas e perfeitas amizades; obra que é o testemunho de vida e da própria variação, da inconstância e fluidez constitutivas da sua experiência pessoal.

Pensamos que Montaigne atribuirá à amizade a função "terapêutica" de dar forma ao eu em cada encontro. $\mathrm{O}$ amigo possibilita a construção de um eu ao amigo, e lhe dá vida; um eu pontual, aprendendo-se agora como fluidez e instabilidade, experimentando no outro que morre a cada instante, o ponto de apoio e referência em meio à névoa do seu constante estranhamento e variação. Não se trata apenas de adaptar-se a cada instante ao imprevisível sopro dos ventos, mas de reconhecer que "somos vento por todos os lados". E ele acrescenta: "O vento ainda, mais sabiamente que nós, gosta de rugir, de se agitar, e se contenta com suas próprias funções, sem desejar a estabilidade, a solidez, qualidades que não são suas" (MONTAIGNE, 1972, livro III, p. 13).

Com a mutualidade em Ferenczi e a amizade em Montaigne, o dispositivo amizade-clínica passa a funcionar como uma composição de linhas de forças heterogêneas que desencadeiam processos de produção de novos modos de pensar/fazer a clínica e o acompanhamento terapêutico, os papéis de terapeuta e paciente, de acompanhante e acompanhado, constituindo-se a partir daí uma clínica em devir ou o devir da/na clínica.

\section{Da distância}

Outra cartografia possível para se pensar a clínica, o acompanhamento terapêutico e suas ressonâncias com a amizade, é refletir sobre o que há de definitivamente distante na relação entre os amigos, entre o acompa- 
nhante e o acompanhado, e que provoca a abertura para a alteridade e para a composição de novos modos de viver e de se relacionar.

Não mais através da mutualidade, da simetria e da horizontalidade na relação terapêutica, mas do embate e do abismo que separa os que se vinculam, onde podemos pensar o inimigo como melhor amigo, como aquele que instiga, que força o amigo a tornar-se outro, numa relação de poder que deseja a produção de subjetividade e não de dominação, a liberdade de ambos e não exploração de um pelo outro.

Refletir sobre o conceito de distância pode ser importante para pensar a amizade e sua potência disruptiva na clínica, ver o amigo como aquele que convoca/incita a viver a alteridade na relação que se estabelece e fazer uso desta ideia para pensar um novo lugar para a distância na relação terapêutica, diferente da recorrente relação entre distância e neutralidade institucionalizada na/pela clínica.

Pensar a amizade e a relação terapêutica como encontro à distância, com a capacidade de abertura e sustentação de uma relação com o Fora, numa experiência do que é sem harmonia, sem acordo, que se define pelo embate incessante e afirmativo da vida.

Não aquela amizade harmoniosa e pacífica, pautada por almas siamesas que se encontram por afinidades e semelhanças. Se o acompanhante e o acompanhado têm afinidades, elas se dão pelo fato de estarem num campo de batalhas, de acordos e desacordos, impasses e saídas, momentos de crise e calmaria, acolhimento.

Nietzsche (1994) através de Zaratustra diz que querer amigo é querer guerrear, é preciso poder ser inimigo, pois no amigo deve-se honrar o inimigo. Trata-se de uma guerra sob o signo do desejo de permanência do vínculo, uma paradoxal situação de paz sob o espírito do guerreiro.

Amigo e inimigo são partes constitutivas que exigem não a nudez frente ao outro, a "pura" sinceridade, mas às melhores vestimentas para diante dele se apresentar.

A amizade não é despojamento total, uma suposta virtude celestial ou romântica, nem tampouco um jogo de interesses encobertos pelos impecáveis trajes das aparências sociais. Do amigo não se deve querer saber tudo, como se fosse algo devassável, transparente ou confessional. A amizade é alheia à confissão e ao contrato, mas não prescinde da cumplicidade que se faz por meio de pactos e confrontos que trazem a inimizade e a dúvida em seu bojo (NIETZSCHE, 1994, p.72-73).

A amizade se afirma neste campo movediço e arriscado, isenta de pressupostos virtuosos ou interesses circunstanciais. Ela é heraclítica, flui, não restaura o que passou, mas, reafirma suas propriedades no devir, um devir-amizade.

A amizade é auto superação na medida em que o amigo desafia o outro à diferenciação, mas ela é mais do que isso, na medida em que dá oportunidade para que se saia da solidão do diálogo do indivíduo com sua sombra, que, por vezes, se torna insuportável. Este terceiro que fala, produz uma trégua no intenso diálogo que se tem com a própria sombra, com seus fantasmas e memórias, possibilitando assim, suportar a própria continuidade desta solidão perpétua.

A amizade como relação à distância, pode ser fundamental para que o terapeuta/acompanhante consiga fazer-se presente, acompanhar o paciente no enfrentamento da vida e, ao mesmo tempo, ajudá-lo a encontrar linhas de fuga, saídas criativas diante dos riscos de exposição às forças implacáveis do Fora.

Há um abismo que separa o terapeuta do paciente, o acompanhante do acompanhado, e é exatamente este abismo que possibilita o encontro e a diferenciação.

Para Blanchot (1971) o mais próximo amigo é o mais distante.

Os mais próximos não dizem senão o que lhes foi próximo, mas não dizem o longínquo que se afirmou nessa proximidade, e o longínquo cessa assim que cessa a presença... Devemos renunciar a conhecer aqueles a quem nos liga alguma coisa de essencial; quer dizer, devemos acolhê-los na relação com o desconhecido onde eles nos acolhem a nós também, em nosso distanciamento. A amizade, essa relação sem dependência, sem contingências e onde, entretanto entra toda a simplicidade da vida, passa pelo reconhecimento da estranheza comum que não nos permite falar de nossos amigos, mas somente falar a eles; não fazer deles um tema de conversa (ou de artigos), mas o movimento do entendimento onde, falando a nós, eles reservam, mesmo na maior familiaridade, a distância infinita, esta separação fundamental a partir da qual o que separa torna-se relação (BLANCHOT, 1971, p. 327-328).

Vemos a necessidade de despojamento do acompanhante e do acompanhado para que a relação adquira intensidade e cumplicidade. Esse despojamento não pode se tornar estritamente confessional, de desnudamento da intimidade de um pelo outro estabelecendo uma arriscada relação de poder despótico onde um confessa e outro julga, um interpreta e assinala e o outro ressignifica e é convencido de que aquilo que não sabe é exatamente o que o constitui.

O que define a terapêutica e a faz perdurar vai depender do que acontecer no fluir do encontro entre acompanhante e acompanhado, não se podendo relaxar demais nem tensionar demais, mas manter a prudência necessária para sustentar-se na fronteira, no limite que separa a ignorância e o informe, e possibilita a produção de sentidos e de formas, dadas pontualmente neste incessante processo de subjetivação.

Não há sucesso terapêutico com o alcance da harmonia almejada pelo acompanhado e seu desejo de cessação da dor. Trata-se sempre de um campo de batalhas onde ambos, acompanhante e acompanhado, estão mergulhados na incerteza, procurando sustentar uma relação com o Fora e buscando a calmaria de um território de vida conquistado. 


\section{Amizade e acompanhamento terapêutico}

Entendemos que, para intervir em contextos complexos onde as crises eclodem, são necessários vários recursos terapêuticos, uma atitude de experimentação e o desejo de criação de novas redes de relações sociais para lidar minimamente com o que se apresenta em cada caso.

O dispositivo amizade-clínica não pode ser limitado pelo universo institucionalizado das quatro paredes do consultório. Queremos dizer que a privacidade e o controle do setting terapêutico precisam ser no mínimo, questionados a partir de um enfoque crítico e político em favor da potencialização de um setting ambulante, construído nas composições infinitas dos fluxos do campo social.

Num consultório estabelecemos um setting. Do contrato até a forma como os móveis estão dispostos na sala, temos uma multiplicidade de elementos que fazem parte de um campo onde se estabelece o processo terapêutico. O setting é uma garantia e uma necessidade para a realização do trabalho. $\mathrm{Na}$ prática do acompanhante terapêutico, é evidente que o setting não está colado ao espaço físico: onde quer que estejam terapeuta-paciente, o setting está presente. A esta presença que percorre o espaço físico, a este campo denominou-se setting ambulante (FULGÊNCIO, 1991, p. 234).

Acreditamos no agir clínico a partir da concepção de Arendt (2005) de "agir político". Ela diz que o agir é um segundo nascimento, um milagre, pensar o agir é pensar o "acontecimento". O acontecimento interrompe os processos automáticos de vida social e introduz a contingência, a novidade, a vontade de jogo e experimentação como formas de pensamento e sociabilidade. A definição hegemônica de agir, como cálculo de sequência e consequência das ações é inevitavelmente revista e passa a ser caracterizada por sua ausência de limites e imprevisibilidade de consequências.

Arendt conclui dizendo que o agir enquanto acontecimento se define como essa mistura peculiar de fragilidade e consistência. Destaca que na esfera da ação política, é precisamente o inesperado que acontece com frequência.

Se o sentido da política é a liberdade, é nesse espaço - e não em outro lugar - que temos o direito de esperar milagres. Não porque acreditemos neles, mas porque os homens, na medida em que podem agir, são capazes de levar a cabo o improvável e o imprevisível e levá-lo ao cabo continuamente mesmo sem saber disso (ARENDT, 2005, p. 312).

Para a pensadora a sociedade está organizada a partir de metáforas familiares, é definida como uma espécie de "administração doméstica coletiva", um "conjunto de famílias economicamente organizadas" que resulta no esvaziamento do espaço público e transfere a dita ação política para a segurança dos espaços privados da vida.

Desde o início da Idade Moderna, o homem passou a preocupar-se consigo mesmo e a política é exercida a partir deste eixo, enquanto que para Arendt, o ponto central de toda a política é a preocupação com o mundo. É nesse sentido que pensamos numa clínica com enfoque político a favor da potencialização de um setting ambulante que se efetiva no cotidiano social.
Afirmar a dimensão política da clínica passa pelo entendimento de que as relações duais ou grupais, em consultórios ou na comunidade devem abarcar toda a complexidade da subjetividade contemporânea. As noções de indivíduo e grupo precisam ser desnaturalizadas e passarem a ser entendidas como efeitos pontuais de processos de subjetivação sempre coletivos.

O que importa é que se consiga romper com as relações de poder que determinam o lugar do eu e do outro, do expert e do despossuído de poder/saber. Através de dispositivos revolucionários, criar passagens para atualizar singularidades, sensibilidades coletivas e modos de relação até então inexistentes. Este é um dos sentidos políticos da clínica que fazemos questão de afirmar, inclusive para contrapor a uma psicologia enquanto saber privatizante, cientificista e a serviço da normalização.

As possíveis aproximações com a ideia de amizade podem servir para pensar o "agir político" como uma experimentação de novas formas de sociabilidade que possam vitalizar a dimensão política da/na clínica.

Para nós, uma das estratégias que mais se aproxima desta concepção de clínica que procuramos conhecer e experimentar é o acompanhamento terapêutico porque nos convoca constantemente a viver o inusitado, se afirma na singularidade de cada encontro terapêutico na rua, no quarto, na sala, na praça; se mostra uma estratégia rebelde a todo movimento de institucionalização da prática e atua fortemente no social e no cotidiano.

O acompanhante terapêutico precisa repensar a cada momento, o lugar do saber institucionalizado e se esforçar para, a partir da práxis, criar dispositivos a serviço da aliança entre ele e o acompanhado, nas misturas e diferenciações inerentes a este encontro na vida cotidiana.

A partir desses encontros e práticas de proximidade literal, de mutualidade que muitas vezes ocorre no acompanhamento terapêutico, dispomos de fortes componentes terapêuticos e, ao mesmo tempo, de situações complexas que requerem um manejo singular para lidar com os impasses que se apresentam em cada situação.

Acreditamos que a relação entre acompanhante e acompanhado precisa construir, na medida do possível, sua própria ética, e esta deve preparar o caminho para a criação de formas de vida e de relação, sem prescrever um modo específico de existir ou de se relacionar.

Construir um percurso amistoso que vai da mutualidade, da proximidade, à distância, à alteridade, buscando suas ressonâncias com a teoria e a prática clínica, nos levou à afirmação do dispositivo amizade-clínica que, esperamos que possa servir para pensar uma clínica que se constitui a partir de contextos singulares de crises, de aglomeração de diferenças e de encontros entre amigos.

\section{Referencias}

ARENDT, H. A condição humana. 10. ed. Rio de Janeiro: Forense Universitária, 2005.

ARISTÓTELES. Ética a Nicômaco. In: Aristóteles. Tradução de Leonel Vallandro e Gerd Bornheim. São Paulo: Abril Cultural, 1984. Coleção Os pensadores. 
BIRMAN, J. Ferenczi: escritos psicanalíticos 1909-1933. Rio de Janeiro: Taurus, 1988.

BLANCHOT, M. Lámitié. Paris: Gallimard, 1971.

CARDOSO, S. Paixão da igualdade, paixão da liberdade: a amizade em Montaigne. In: NOVAES, A. (Org.). Os sentidos da paixão. São Paulo: Companhia das Letras, 1987. p. 125-138.

DELEUZE, G. ¿Que és un dispositivo? In: DELEUZE, G. et al. Michel Foucault, filósofo. Barcelona: Gedisa, 1990, p. 155-161.

DELEUZE, G. Crítica e clínica. Tradução de Peter Pál Pelbart. São Paulo: Editora 34, 1997.

FERENCZI, S. Diário Clínico. Tradução de Álvaro Cabral. São Paulo: Martins Fontes, 1990.

FOUCAULT, M. Microfisica do poder. Rio de Janeiro: Graal, 1979.

FOUCAULT, M. De l'amitié comme mode de vie [Da amizade como modo de vida]. Tradução de Wanderson Flor do Nascimento. Gai Pied, Paris, n. 25, p. 38-39, avril, 1981. Disponível em: <http://portalgens.com.br/portal/images/ stories/pdf/amizade.pdf>. Acesso em: 22 set. 2013.

FOUCAULT, M. História da loucura na Idade Clássica. São Paulo: Perspectiva, 1995.

FOUCAULT, M. A ordem do discurso. São Paulo: Loyola, 1996.

FULGÊNCIO, L. Interpretando a história. Acompanhamento Terapêutico de pacientes psicóticos no Hospital-dia A Casa. In: Equipe de Acompanhantes Terapêuticos do Hospital-dia A Casa (Org.). A rua como espaço clínico, Acompanhamento Terapêutico. São Paulo: Escuta, 1991. p. 231-236.

GUATTARI, F. Caosmose: um novo paradigma estético. Tradução de Ana Lúcia de Oliveira e Lúcia Cláudia Leão. São Paulo: Editora 34, 1992.

LAPLANCHE, J.; PONTALIS, J. B. (Org.). Vocabulário de Psicanálise. Tradução de Pedro Tamen. São Paulo: Martins Fontes, 2001.

MAUER, S. K.; RESNISKY, S. Acompanhantes terapêuticos e pacientes psicóticos: manual introdutório a uma estratégia clínica. Campinas: Papirus, 1987.

MONTAIGNE, M. Ensaios. São Paulo: Abril Cultural, 1972. livro 3.

NIETZSCHE, F. Assim falou Zaratustra: um livro para todos e para ninguém. Rio de Janeiro: Bertrand Brasil, 1994.

ORTEGA, F. Genealogias da amizade. São Paulo: Iluminuras, 2002.

PELBART, P. P. Da clausura do fora ao fora da clausura: loucura e desrazão. São Paulo: Brasiliense, 1989.

ROLNIK, S. B. Hal Hartley et l'éthique de la confiance. Trafic. Révue de Cinéma, [S.1.], n. 12, p. 104-115, 1994.

ROLNIK, S. B. À sombra da cidadania: alteridade, homem da ética e reinvenção da democracia. In: MAGALHÃES, M. C. R. (Org.). Na sombra da cidade. São Paulo: Escuta, 1995. p. 103-119.

SENNETT, R. O declínio do homem público: a tirania das intimidades. Tradução de Lygia Araújo Watanabe. São Paulo: Companhia das Letras, 1995.
SERENO, D.; AGUIAR, C. C. T.; MENDONÇA, L. O Acompanhamento Terapêutico e a Clínica: a função do acompanhante no tratamento. In: Equipe de Acompanhantes Terapêuticos do Hospital-dia A Casa (Org.). A rua como espaço clínico, acompanhamento terapêutico. São Paulo: Escuta, 1991. p. 67-78.

Recebido em: 7 de outubro de 2013 Aceito em: 8 de outubro de 2015 